\title{
Triptolide decreases expression of latency-associated nuclear antigen 1 and reduces viral titers in Kaposi's sarcoma-associated and herpesvirus-related primary effusion lymphoma cells
}

\author{
CONG LONG $^{1}$, WEI GUO ${ }^{2}$, HENG ZHOU $^{1}$, JINGCHAO WANG $^{1}$, HUAN WANG $^{1}$ and XIAOPING SUN ${ }^{1,3}$ \\ ${ }^{1}$ Department of Pathogen Biology, School of Basic Medical Sciences, Wuhan University, Wuhan, Hubei 430071; \\ ${ }^{2}$ Department of Pathology and Physiology, School of Basic Medical Sciences, Wuhan University, Wuhan, \\ Hubei 430071; ${ }^{3}$ State Key Laboratory of Virology, Wuhan University, Wuhan, Hubei 430072, P.R. China
}

Received October 30, 2015; Accepted January 11, 2016

DOI: $10.3892 /$ ijo.2016.3353

\begin{abstract}
Kaposi's sarcoma-associated herpesvirus (KSHV) can establish a life-long persistence in the host after primary infection and is associated with certain malignancies, which are resistant to conventional chemotherapeutic agents with a poor prognosis. Latency-associated nuclear antigen 1 (LANA1) encoded by KSHV is essential for segregation, replication and maintenance of viral genome. In addition, LANA1 upregulates the transcriptional activity of signal transducer and activator of transcription 3 (STAT3), which plays an important role in promoting survival of KSHV-associated primary effusion lymphoma (PEL) cells. Furthermore, LANA1 mediates transcriptional modulation of KSHV and host genome in host cells. In the present study, the antitumor effect of triptolide was assessed. CCK-8 assays were performed to demonstrate that the proliferations of PEL cells were efficiently inhibited by triptolide in a dose- and time-dependent manner. Flow cytometric results indicated that triptolide induced cell cycle arrest and apoptosis. Western blot results suggested that triptolide downregulated LANA1 expression and reduced half-life of LANA1 in the KSHV-infected malignant cells. Viral titer experiments indicated that triptolide treatment impaired the number of viral DNA copies and the production of virions in BCBL-1 cells. Triptolide also suppressed STAT3 activity and inhibited secretion of IL-6 in PEL cells. In a mouse xenograft model of primary effusion lymphoma by BCBL-1 cells, triptolide treatment significantly inhibited ascites formation and diffused organ infiltration. These results indicate that triptolide impairs the expression of LANA1 and shows antitumor
\end{abstract}

Correspondence to: Professor Xiaoping Sun, Department of Pathogen Biology, School of Basic Medical Sciences, Wuhan University, 185 Eastlake Road, Wuhan, Hubei 430071, P.R. China E-mail: xsun6@whu.edu.cn

Key words: triptolide, latency-associated nuclear antigen 1, viral titers, Kaposi's sarcoma-associated herpesvirus, primary effusion lymphoma activity against PEL in vitro and in vivo. Triptolide may be a potential agent for treatment of PEL.

\section{Introduction}

Kaposi's sarcoma-associated herpesvirus (KSHV), a gammaherpesvirus, is associated with Kaposi's sarcoma (KS) and several lymphoproliferative diseases, including primary effusion lymphoma (PEL) and multicentric Castleman's disease (MCD) (1). PEL, which was originally identified in patients with advanced AIDS, belongs to a variant of non-Hodgkin's B lymphoma showing serious lymphomatous effusion in body cavities. Although treated with cytotoxic chemotherapeutic agents, prognosis of patients is extremely poor upon diagnosis, with a median survival times of 3-6 months (2). Similar to the other herpesviruses, KSHV infection can be divided into latent and lytic stages and can establish a life-long persistence in the host after primary infection (3). During the latent infection stage, only a limited set of genes are expressed, including open reading frame $(\mathrm{Orf}) 71, \operatorname{Orf} 72, \operatorname{Orf} 73$, viral-encoded microRNAs. After reactivating and entering lytic stage, most viral genes are expressed in an orderly fashion based on the time of expression, defined as immediate-early, early and late genes, which facilitate genomic DNA replication and mature virion production $(4,5)$.

Currently, candidate drugs for management of KSHVrelated diseases can be divided in two groups, which include compounds targeting viral DNA polymerase or not. DNA polymerase inhibitors are mainly involved in nucleoside analogs, acyclic nucleoside phosphonates, pyrophosphate analogs and non-nucleoside analogs. Non-DNA polymerase inhibitors, which target viral or cellular proteins, include compounds isolated from plants (6). For example, resveratrol, a nonflavonoid polyphenol derived from Polygonum cuspidatum, was demonstrated to decrease ERK1/2 activity and expression of Egr-1 in KSHV-infected cells, resulting in inhibition of KSHV reactivation from latency (7). Additionally, DD2, a benzyl-substituted 4-(pyridine-2-amido) benzoic acid, trapped an inactive monomeric conformation, resulting in disruption of KSHV proteasomal dimerization (8). Despite the fact that various antiviral agents are known to inhibit KSHV replica- 
tion, studies on these pre-drugs, mainly in vitro, are limited due to toxic effect or incomplete efficiency. Moreover, these antiviral agents can not eliminate persistent latent KSHV. To date, there are no standard therapeutic guidelines for the treatment of KSHV-infected diseases, and little progress has been made since the discovery of KSHV 20 years ago.

Latency-associated nuclear antigen 1 (LANA1), encoded by KSHV $\operatorname{Orf} 73$, is a viral oncoprotein that contributes to tumorigenesis (9). LANA1 is a protein expressed in all KSHVinfected cells and is required for viral genomic establishment and maintenance in the nucleus (10). As a master regulator of KSHV latency, LANA1 can also be considered as a transcriptional modulator for host cell genes, resulting in dysregulation of several pathways (11). For example, LANA1 can regulate the Wnt pathway by nuclear trapping of glycogen synthase kinase $3 \beta$ (GSK3 $\beta$ ), resulting in stabilizing of $\beta$-catenin (12). LANA1 is essential for KSHV-induced angiogenesis and can activate phosphorylation of survivin, which contributes to cell proliferation and viral latent replication $(13,14)$. LANA1 has also been shown to enhance transactivation of human telomerase reverse transcriptase (hTERT) promoter by interacting with transcription factor specificity protein 1 (Sp1), therefore, contributing to immortalization of PEL cells (15). Additionally, LANA1 targets degradation of the mitotic checkpoint kinase Bub1, resulting in chromosomal instability, and facilitates establishment of viral latency through interacting with Krüppel-associated box domain associated protein-1 (KAP1) $(16,17)$. LANA1 also interacts with tumor suppressors, such as $\mathrm{p} 53$ and $\mathrm{Rb}$ proteins, leading to disruption of their tumor-suppressive functions $(18,19)$. Moreover, LANA1 enhances transcriptional activity of signal transducer and activator of transcription 3 (STAT3) via physical and functional interaction with STAT3 (20). Collectively, the biological insights into LANA1 make it a promising rational target for therapeutic strategies.

Triptolide, a diterpenoid triepoxide, is purified from the roots of Chinese herb Tripterygium wilfordii (21). Triptolide displays a broad-spectrum bioactivity profile, including antitumor, anti-inflammatory, immunosuppressive and antifertility effects. It has been used for treatment of autoimmune diseases such as rheumatoid arthritis (22). In addition, triptolide has been reported to inhibit proliferation and induce apoptosis against a variety of tumor cell lines in vitro, including cholangiocarcinoma, melanoma, breast, gastric cancer and non-small cell lung carcinoma (23). Triptolide can also induce pancreatic cancer cell death via inhibition of Hsp70 and O-GlcNAc modification of transcription factor Sp1 $(24,25)$. Currently, triptolide has entered clinical trials for treatment of diseases including psoriasis vulgaris, diabetic nephropathy and nephritic syndrome. Minnelide, a water-soluble pre-drug of triptolide, has also entered clinical trials for treatment of pancreatic cancer showing good patient toleration profile (26). However, little is known about effect of triptolide on KSHV-associated PEL.

Previously, our laboratory found that Hsp90 inhibitors inhibit outgrowth of Epstein-Barr virus (EBV, another gammaherpesvirus closely related to KSHV)-infected malignant cells via downregulation of EBV nuclear antigen 1 (EBNA1) (27). A small molecule pre-drug 17-DMAG (an Hsp90 inhibitor) also decreases expression of conserved herpesvirus protein kinases in EBV-infected malignant cells (28). Recently, we found that triptolide inhibited proliferation of latency III type infected EBV-positive B lymphocytes through the virus latent membrane protein 1 (LMP1)-dependent mechanism (29). In the present study, our results demonstrate that triptolide can effectively inhibit cell proliferation and induce cell apoptosis in the PEL cells. Furthermore, triptolide specifically decreases LANA1 expression without reducing the LANA1 transcript level. LANA1 accumulates after treatment with proteasomal inhibitor MG-132 in the absence or presence of triptolide. It is also indicated that triptolide reduces the half-life of LANA1. In addition, the number of viral DNA copies and the production of virions are reduced by triptolide. Moreover, triptolide inhibited expression of the phosphorylated STAT3 and secretion of IL-6. Finally, we also show that the KSHV-induced lymphoproliferative diseases in non-obese diabetic/severe combined immunodeficient (NOD-SCID) mice are strongly inhibited by a non-toxic dose of triptolide.

\section{Materials and methods}

Cell lines and reagents. PEL cells (BCBL-1, JSC-1 and BC-3) and a Burkitt lymphoma cell line, BJAB, were gifts kindly provided by Professor K. Lan (Institute Pasteur of Shanghai, Chinese Academy of Sciences, Shanghai, China). P3HR-1 cells (EBV-positive and KSHV-negative) were kindly provided by Professor Y. Cao (Central South University, Changsha, China). Peripheral blood mononuclear cells (PBMCs) were isolated from healthy donors by using Ficoll-Paque Premium (GE Healthcare, Uppsala, Sweden) according to the manufacturer's instructions. Human renal embryonic 293T cells and HeLa cells, which were purchased from the American Type Culture Collection (ATCC; Manassas, VA, USA), were obtained from Professor H. Li (Wuhan University, Wuhan, China).

BJAB, P3HR-1, BCBL-1, BC-3, JSC-1 cells and PBMCs were maintained in RPMI-1640 medium containing $10 \%$ fetal bovine serum (FBS; Gibco-BRL, Gaithersburg, MD, USA). HeLa and 293T cells were cultured in DMEM containing 10\% FBS. The whole cell lines were cultured at $37^{\circ} \mathrm{C}$ with $5 \% \mathrm{CO}_{2}$ and $100 \%$ humidity.

Triptolide(Sigma,St.Louis,MO,USA),12-O-Tetradecanoylphorbol-13-Acetate (TPA; Sigma), cidofovir (CDV; Selleck Chemicals, Shanghai, China), cycloheximide (CHX; Sigma), and MG-132 (Calbiochem, Billerica, MA, USA) were dissolved in dimethylsulfoxide (DMSO). Sodium butyrate (NaB; Sigma) was dissolved in PBS.

Plasmids. Plasmid DNA was purified through columns (Axygen Scientific Inc., Union City, CA, USA) as described by the manufacturer. The plasmid pSG5-LANA1 was constructed

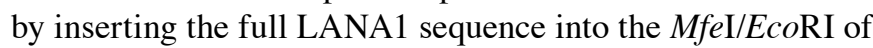
pSG5 vector (YouBio, Shanghai, China).

Cell viability assay. The viability of cells was determined by the Cell Counting kit-8 assay (CCK-8; Dojindo Laboratories, Kumamoto, Japan). In brief, cells were seeded in 96-well plates at a density of $1 \times 10^{4} / 100 \mu \mathrm{l}$ culture medium. All the cells were treated with vehicle control (DMSO; $0.006 \%$, vol/vol) or increasing concentrations of triptolide for 24,48 and $72 \mathrm{~h}$. 
After different treatments, $10 \mu \mathrm{l}$ of tetrazolium substrate was added into each well of the plate. The plates protected from light were incubated at $37^{\circ} \mathrm{C}$ for $1 \mathrm{~h}$. The optical density (OD) was determined at an absorbance of $450 \mathrm{~nm}$ using an ELx800 microimmunoanalyser (BioTek Instruments, Inc., Winooski, VT, USA).

Cell transfection. For transfection, KSHV-negative HeLa cells were transiently transfected using X-tremeGENE HP DNA Transfection reagent (Roche, Basel, Switzerland) with pSG5 (the empty vector) or pSG5-LANA1 according to the manufacturer's protocol. At $4 \mathrm{~h}$ post-transfection, cells were treated with vehicle control (DMSO; $0.006 \%$, vol/vol) or triptolide for further $44 \mathrm{~h}$ before cell harvesting. In some experiments, cells were treated in the absence or presence of MG-132 $(10 \mu \mathrm{M})$ or CHX $(25 \mu \mathrm{g} / \mathrm{ml})$.

Immunoblot analysis. Briefly, cells treated in different conditions were collected and washed with ice-cold PBS twice. Whole cell lysates were prepared in RIPA lysis buffer (Beyotime Institute of Biotechnology, Shanghai, China) supplemented with $0.5 \%$ cocktail protease inhibitor (Roche) and $0.5 \mathrm{mM}$ phenylmethylsulfonyl fluoride (PMSF). The cell lysates harvested were sonicated for $15 \mathrm{sec}$, followed by centrifugation at $12,000 \mathrm{x}$ g for $10 \mathrm{~min}$. The supernatants were collected and transferred into new tubes. Protein concentrations were measured by the bicinchoninic acid method using bovine serum albumin as a standard. Based on the measurement of protein concentrations of all samples in the same experiment, the loading volumes of samples were accordingly adjusted. Therefore, equal amounts of proteins mixed with $5 \mathrm{X}$ loading buffer [250 nM Tris-Hcl (pH 6.8), 10\% SDS, $0.5 \%$ $\mathrm{BPB}, 50 \%$ glycerol, $5 \% \beta$-mercaptoethanol] were subjected to $10 \%$ SDS-PAGE gels. The gels were run at $100 \mathrm{~V}$, followed by transfer to PVDF membranes (Bio-Rad Laboratories, Inc., Hercules, CA, USA). The membranes were blocked with 5\% skim milk in TBST, followed by incubation with primary antibodies overnight at $4^{\circ} \mathrm{C}$. After $3 \times 5$-min washes in TBST, the membranes were incubated with appropriate horseradishperoxidase-conjugated secondary antibodies for $1 \mathrm{~h}$. The primary antibodies used were as follows: GAPDH (cat. no. 10494-1-AP, 1:5,000; Proteintech, Wuhan, China), $\beta$-actin (cat. no. A5441, 1:5,000; Sigma), LANA-1 (cat. no. 13-210-100, 1:4,000; Abionline, Cambridge, UK), vIL-6 (cat no. 13-214050, 1:1,000; Abionline), v-Cyclin (cat no. F105P, 1:1,000; Exalpha Biological, Inc., Boston, MA, USA), STAT3 (cat no. 9139, 1:1,000; Cell Signaling Technology, Danvers, MA, USA), phospho-STAT3 (cat. no. 4113, 1:1,000; Cell Signaling Technology) caspase-3 (cat. no. 9668, 1:1,000; Cell Signaling Technology), cleaved caspase-3 (cat. no. 9664, 1:1,000; Cell Signaling Technology), RTA (cat. no. 251345, 1:500; Abbiotec LLC, San Diego, CA, USA). A rabbit polyclonal antibody against v-Flip was raised in our laboratory. The secondary antibodies were horseradish-peroxidase-conjugated secondary anti-mouse IgG (1:10,000; Wuhan Kerui Technology Co., Ltd., Wuhan, China), anti-rabbit IgG (1:10,000; Wuhan Kerui Technology), or anti-rat IgG (1:5,000; Wuhan Kerui Technology). Antibody-bound proteins were detected using the ECL system (Bio-Rad Laboratories). Image quantifications were performed using ImageJ software.
RNA extraction, $c D N A$ preparation and quantitative real-time PCR. PEL cells treated with vehicle control (DMSO; 0.006\%, $\mathrm{vol} / \mathrm{vol}$ ) or triptolide for 24 and $48 \mathrm{~h}$ were harvested and the total RNA was extracted using TRIzol reagent (Invitrogen) according to the manufacturer's instructions. The concentration of total RNA was determined by NanoDrop 2000 (Thermo Fisher Scientific, Waltham, MA, USA), and all isolated RNA samples (A260/A280 ratio $>1.8$ ) were stored at $-80^{\circ} \mathrm{C}$. Total RNA $(1 \mu \mathrm{g})$ was reversely transcribed using a PrimeScript RT reagent kit with gDNA Eraser (cat. no. RR047A; Takara Bio, Tokyo, Japan). Genomic DNA elimination reactions were performed in a volume of $10 \mu \mathrm{l}$ containing $2 \mu \mathrm{l}$ of $5 \mathrm{X}$ gDNA Eraser buffer, $1 \mu \mathrm{l}$ of gDNA Eraser, and $7 \mu \mathrm{l}$ of RNase-free $\mathrm{dH}_{2} \mathrm{O}$ and the total RNA $(1 \mu \mathrm{g})$, followed by storage at room temperature for $30 \mathrm{~min}$. The reverse-transcription reaction mixture $(20 \mu \mathrm{l})$ included $4 \mu \mathrm{l}$ of $5 \mathrm{X}$ PrimeScript buffer 2, $1 \mu \mathrm{l}$ of PrimeScript RT Enzyme Mix I, $1 \mu \mathrm{l}$ of RT Primer Mixture containing oligo dT primer and random 6 mers, $4 \mu \mathrm{l}$ of RNase-free $\mathrm{dH}_{2} \mathrm{O}$, and $10 \mu \mathrm{l}$ of genomic DNA elimination reaction solution as mentioned above. The condition for reverse-transcription reaction was $15 \mathrm{~min}$ at $37^{\circ} \mathrm{C}$ and $5 \mathrm{sec}$ at $85^{\circ} \mathrm{C}$. Expression of viral LANA1 mRNAs was quantified by quantitative PCR using a SYBR-Green PCR kit (cat no. RR420A; Takara Bio). Quantitative PCR reaction mixtures (20 $\mu$ l) included 1X SYBR Premix Ex Taq II (Tli RNaseH Plus), $0.4 \mu \mathrm{M}$ each primer and $1 \mu \mathrm{l} \mathrm{cDNA}$ reaction mixture (equivalent to $50 \mathrm{ng}$ of input RNA). Reaction was performed by a CFX96 Real-Time PCR detection system (Bio-Rad Laboratories) and included an initial $30 \mathrm{sec}$ denaturation step at $95^{\circ} \mathrm{C}$, followed by 40 cycles of $10 \mathrm{sec}$ at $95^{\circ} \mathrm{C}, 10 \mathrm{sec}$ at $60^{\circ} \mathrm{C}$ and $15 \mathrm{sec}$ at $72^{\circ} \mathrm{C}$. Melting curve analysis was performed between 65 and $95^{\circ} \mathrm{C}$ (with $0.5^{\circ} \mathrm{C}$ increments) to verify amplicon specificity. The average cycle threshold (CT) was determined by three independent samples. Template-negative (quantitative PCR reaction mixtures without cDNA) and RT-negative (RNA after genomic DNA elimination) conditions were used as controls. The relative amounts of LANA1 transcript were normalized to the housekeeping gene GAPDH and quantitative PCR data for the relative quantification were calculated with the ${ }^{\Delta \Delta} \mathrm{Ct}$ method. The level of LANA1 transcript in cells treated with vehicle control (DMSO; 0.006\%, $\mathrm{vol} / \mathrm{vol}$ ) was set as 1 . The primers were as follows: LANA1 forward, 5'-CGAGAGGAAGTTGTAGGAAACG-3' and LANA1 reverse, 5'-CTTCCAGGTATAGGCAAGGTG-3' (30); GAPDH forward, 5'-ACATCGCTCAGACACCATG-3' and GAPDH reverse, 5'-TGTAGTTGAGGTCAATGAAGGG-3' (30). All experiments were repeated from three independent cultures.

Flow cytometric analysis. PEL cells were seeded in 6-well plates and treated with vehicle control (DMSO; $0.006 \%$, $\mathrm{vol} / \mathrm{vol}$ ) or triptolide (50 or $100 \mathrm{nM}$ ) for $24 \mathrm{~h}$, respectively. For apoptosis analysis, PEL cells were evaluated with Annexin V-FITC/propidium iodide (PI) apoptosis detection kit (Multisciences, Shanghai, China). Briefly, $2 \times 10^{5}$ cells were washed 3 times with PBS and resuspended in $500 \mu 1$ of $1 \mathrm{X}$ binding buffer, followed by adding $5 \mu \mathrm{l}$ of Annexin V-FIFC and $10 \mu \mathrm{l}$ of PI. The whole cells were analyzed immediately by a Beckman-Coulter system (EPICS Altra II; BeckmanCoulter, Fullerton, CA, USA). 
A

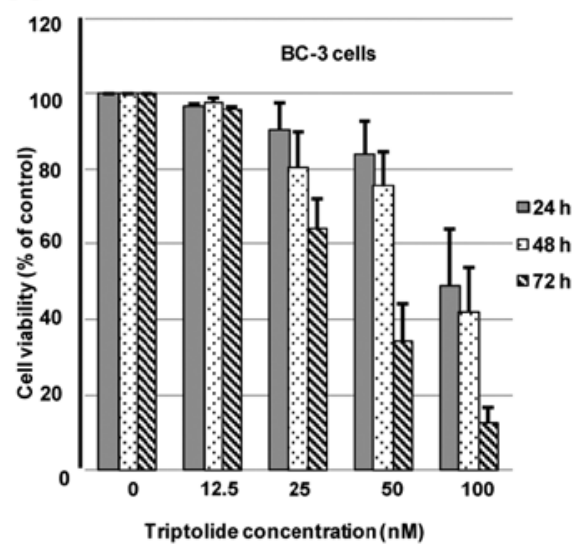

D

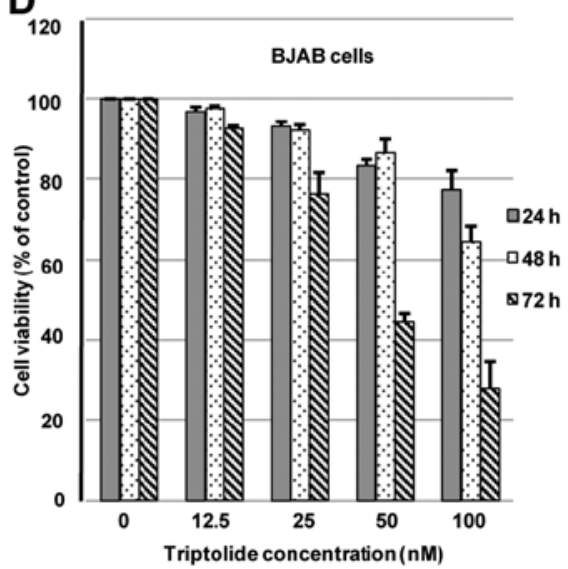

B

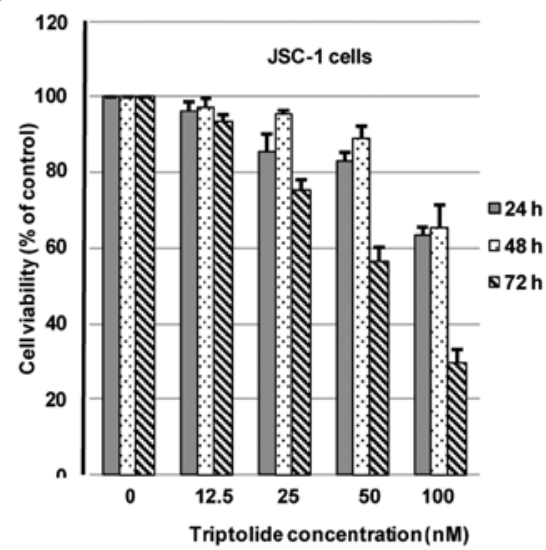

E

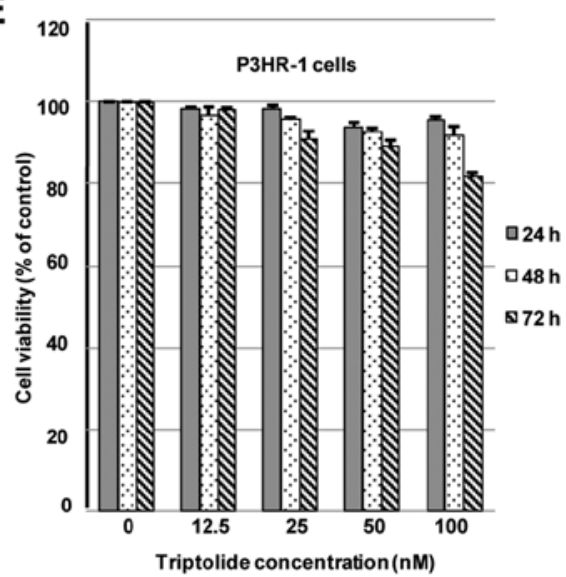

C

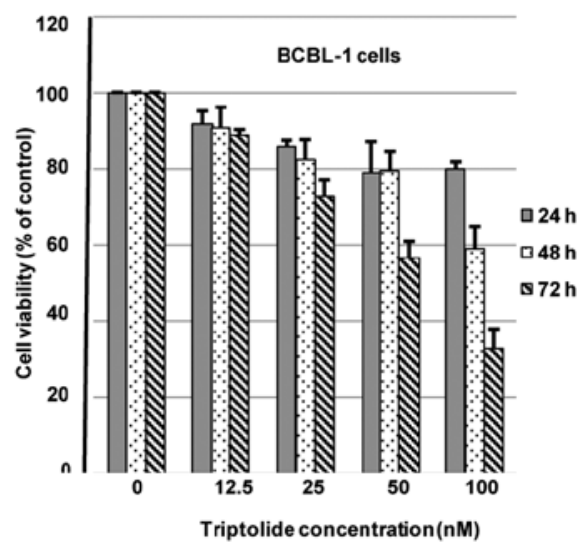

F

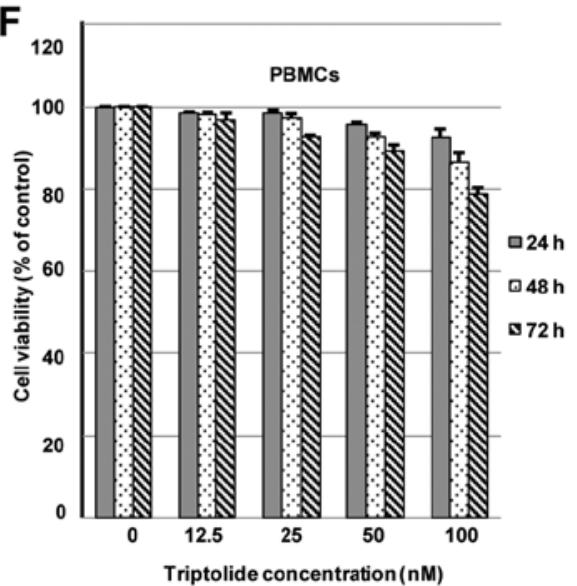

Figure 1. Triptolide inhibits cell proliferation in vitro. The effects of triptolide on cell viability. (A) BC-3, (B) JSC-1, (C) BCBL-1, (D) BJAB, (E) P3HR-1 cells, and (F) PBMCs were treated with vehicle control or a series of increasing concentrations of triptolide for 24,48 and $72 \mathrm{~h}$, respectively. The cell viabilities were measured by CCK- 8 assay. The values shown are mean \pm SD of 3 independent experiments carried out in triplicate.

Progeny virus analysis. TPA $(20 \mathrm{ng} / \mathrm{ml})$ and $\mathrm{NaB}(1.2 \mathrm{mM})$ were used to induce BCBL-1 cells entering lytic replication. At $3 \mathrm{~h}$ post-induction, cell medium was replaced and cultured in the absence or presence of triptolide for further $48 \mathrm{~h}$. KSHV virion-associated DNA derived from the supernatants was collected according to the method previously described (31). Equal amounts of the viral lysate were used for the quantitative real-time PCR assay of the KSHV specific region, $\operatorname{Orf} K 9$. The primer pair for $\operatorname{Orf} K 9$ was: $\operatorname{Orf} K 9$ forward, 5'-GTCTCTGCGCCATTCAAAAC-3' and $\operatorname{Orf} K 9$ reverse, 5'-CCGGACACGACAACTAAGAA-3'. Intracellular viral DNA in BCBL-1 cells was extracted with Phenol-Chloroform method according to the manufacturer's instructions. The copy numbers of KSHV genome were evaluated by a quantitative real-time PCR assay.

Enzyme-linked immunosorbent assay (ELISA). PEL cells were treated with or without $100 \mathrm{nM}$ triptolide for 24,48 , and $72 \mathrm{~h}$, respectively. Cell supernatants were collected and subjected to ELISA. IL-6 level of the cell supernatants was measured using human IL-6 ELISA kit (Multisciences) according to the manufacturer's instructions.

In vivo xenograft model. The animal protocol used in the present study was approved by the Medical Ethics Committee of Wuhan University. NOD/SCID mice were maintained under specific pathogen-free conditions in the Animal Experiment Center of Wuhan University, Animal Biosafety Level-III Laboratory.

BCBL-1 cells were inoculated intraperitoneally (i.p.) into the flank of 4-week-old female NOD/SCID mice (purchased from Beijing HFK Bioscience, Co., Ltd., Beijing, China). Twelve mice were injected with BCBL- 1 cells at $1 \times 10^{7}$ per mouse on day 0 . Three days post-injection, the mice were randomly divided into vehicle and treatment groups (six mice per group), and daily i.p. injection of triptolide $(0.4 \mathrm{mg} / \mathrm{kg})$ or PBS was performed. After 21 days of treatment, all the mice were sacrificed by cervical dislocation. Tumor burden was evaluated by measuring body weight and volume of ascites. Tissue samples were collected and fixed in $10 \%$ neutral buffered formalin, embedded and sectioned at $5 \mu \mathrm{m}$. Hematoxylin and eosin staining for histological analysis and immunohistochemistry analysis were performed as previously described (32).

Statistical analysis. Data were presented as the mean \pm standard deviation (mean $\pm \mathrm{SD}$ ) of three separate experiments. The statistical significance of the difference was determined by the Student's t-test, and P-values $<0.05$ were considered to indicate a statistically significant result. 
A
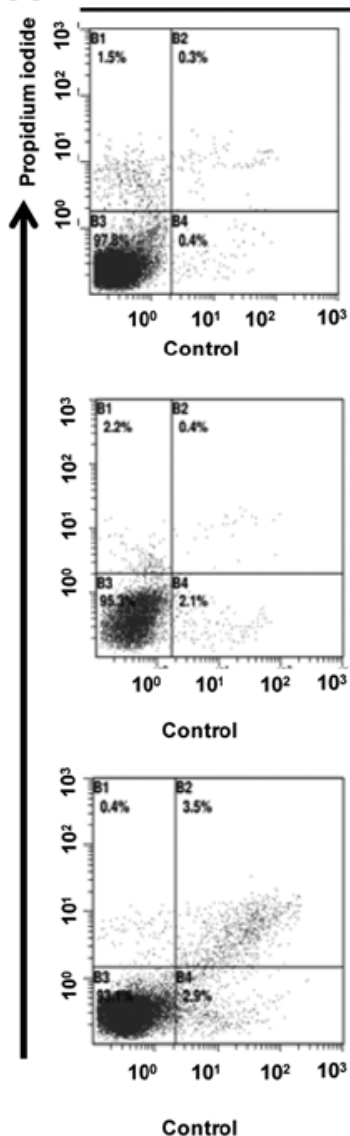

Control
$24 \mathrm{~h}$
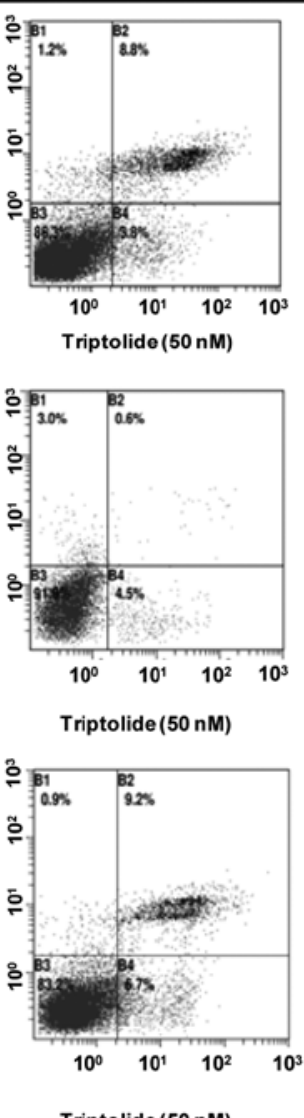

Triptolide (50 nM)
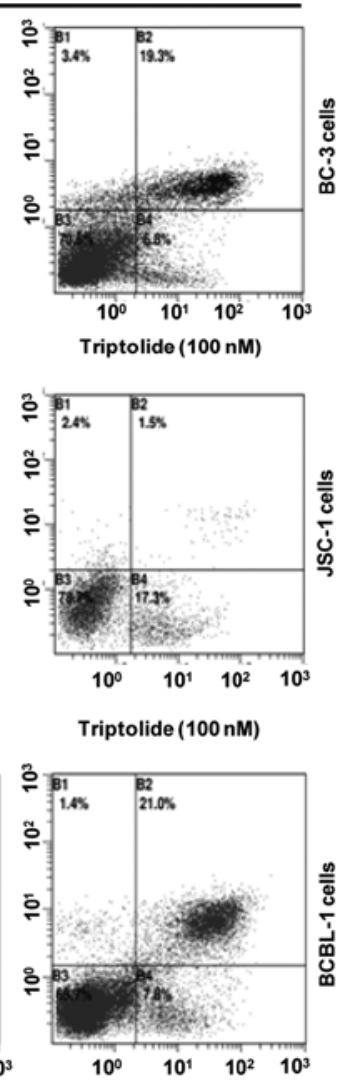

Triptolide (100 nM)
B

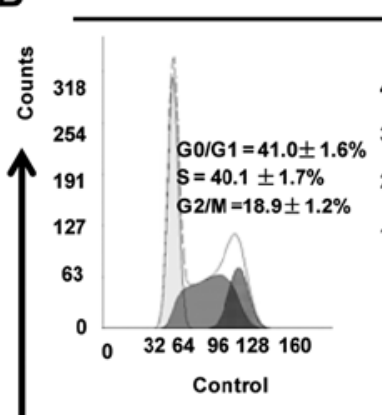

$24 \mathrm{~h}$
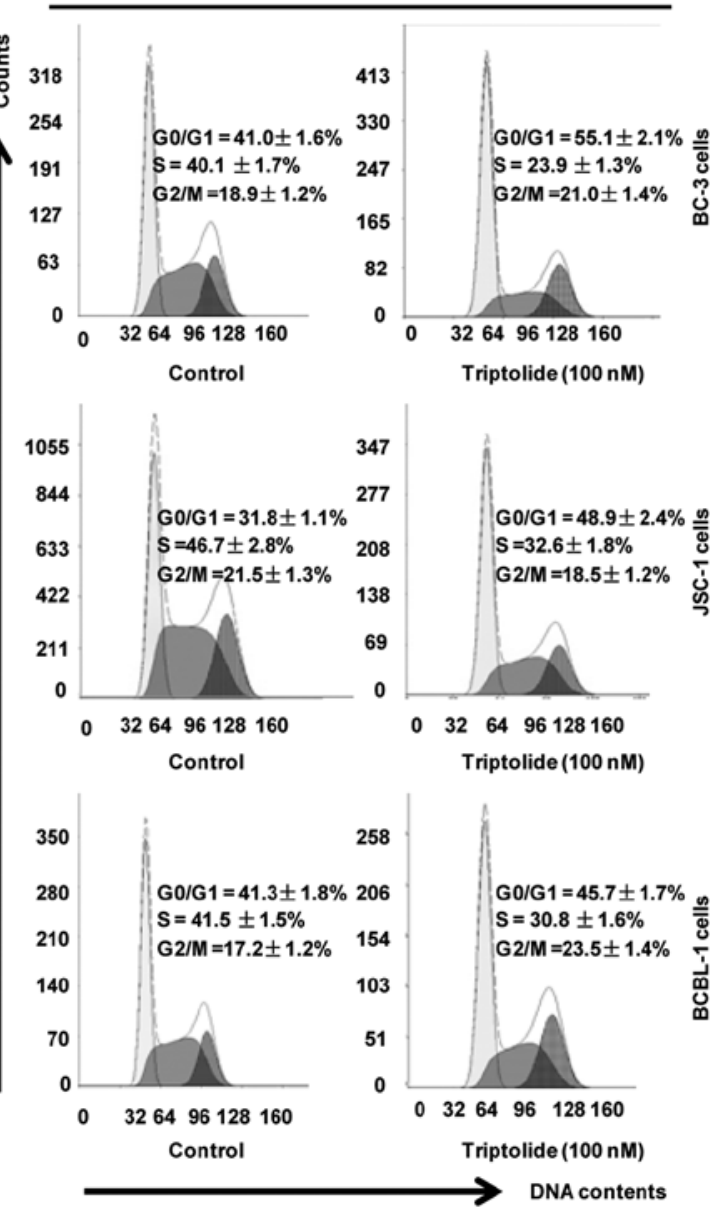

Figure 2. Triptolide induces cell cycle arrest and apoptosis in the KSHV-associated PEL cells. (A) The effects of triptolide on apoptosis. BC-3, JSC-1 and BCBL-1 cells were treated with vehicle control or indicated triptolide for $24 \mathrm{~h}$, followed by straining with Annexin V-FITC/PI. Apoptotic cells were assessed by flow cytometry. (B) The effects of triptolide on cell cycle. BC-3, JSC-1 and BCBL-1 cells were treated with vehicle control or indicated triptolide for $24 \mathrm{~h}$, respectively, followed by straining with PI. Cell cycle analysis was performed using flow cytometry.

\section{Results}

Triptolide inhibits proliferation of KSHV-associated PEL cells. To determine whether triptolide specifically targets cell viability in the KSHV-associated PEL cells, BC-3, BCBL-1 and JSC-1 cells, together with KSHV-negative BJAB cells were treated with vehicle control or a series of increasing concentrations of triptolide for 24,48 and $72 \mathrm{~h}$, respectively. Cell viability was determined by CCK- 8 assays. Triptolide inhibited cell viability of BC-3 cells in a dose- and timedependent manner, with $50 \%$ inhibitory concentration $\left(\mathrm{IC}_{50}\right)$ values of 108.3, 89.5 and 46.4 nM by a 24-, 48- and 72-h triptolide treatment, respectively (Fig. 1A). Similar experiments were conducted in the other two PEL cells. The $\mathrm{IC}_{50}$ values were calculated as $143.3,128.3$ and $67.9 \mathrm{nM}$ in JSC-1 cells and 153.9, 119.6 and $69.1 \mathrm{nM}$ in BCBL-1 cells by 24-, 48- and 72-h triptolide treatment, respectively (Fig. 1B and C). In addition, triptolide inhibited cell proliferation to a similar degree in BJAB cells, and the $\mathrm{IC}_{50}$ values were calculated as 146.6, 115.6 and $63.8 \mathrm{nM}$ by 24-, 48- and 72-h triptolide treatment, respectively (Fig. 1D).

To further evaluate the antiproliferative effects of triptolide on KSHV-uninfected B cell line, P3HR-1 cells and PBMCs isolated from healthy donors were treated with vehicle control or a series of increasing concentrations of triptolide for 24 , 48 and $72 \mathrm{~h}$, respectively. Our previous results indicated that 100-nM triptolide treatment for 4 days decreased cell viability by $<20 \%$ in P3HR-1 cells (28). As shown in Fig. 1E, a series of increasing concentrations of triptolide treatment for 24, 48 and $72 \mathrm{~h}$ showed slight proliferation inhibition in P3HR-1 cells. Similar results were also found in PBMCs treated by a series of increasing concentrations of triptolide (Fig. 1F). These results suggested that triptolide efficiently inhibited cell viability in PEL cells, but not significantly in PBMCs and P3HR-1 cells.

Triptolide induces cell cycle arrest and apoptosis in the $K S H V$-associated PEL cells. To examine the effect of triptolide on induction of cell cycle arrest and apoptosis, BC-3, JSC-1 and BCBL-1 cells were treated with vehicle control or indicated triptolide for $24 \mathrm{~h}$. Cell cycle arrest and apoptosis were analyzed by flow cytometry. As shown in Fig. 2A, treatment of PEL cells with triptolide resulted in apoptosis in a dose-dependent manner, which was confirmed by staining with Annexin V-FITC/PI. In addition, treatment with $100 \mathrm{nM}$ triptolide for $24 \mathrm{~h}$ could induce cell apoptosis in BJAB cells, 

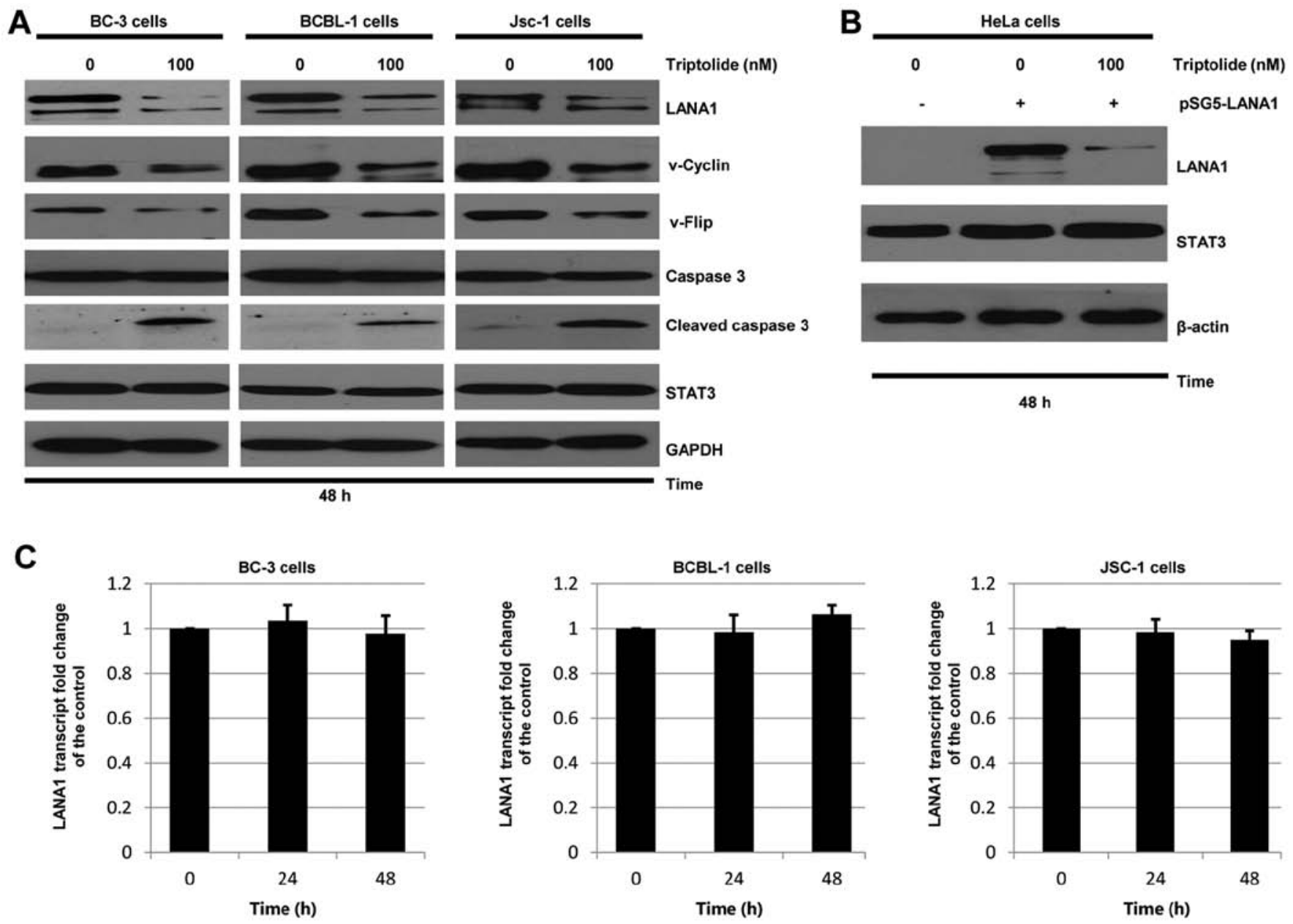

Figure 3. Triptolide downregulates LANA1 expression. (A and B) LANA1 degradation induced by triptolide. (A) BC-3, BCBL-1 and JSC-1 cells were treated with vehicle control or triptolide (100 nM) for $48 \mathrm{~h}$, respectively. (B) HeLa cells were transfected with empty vector (pSG5) or pSG5-LANA1 as indicated, followed by a 44-h treatment with $100 \mathrm{nM}$ triptolide beginning at $4 \mathrm{~h}$ after transfection. Whole-cell extracts were prepared and western blotting was performed to analyze expression of LANA1 $(20 \mu \mathrm{g})$, v-Cyclin $(20 \mu \mathrm{g})$, v-Flip $(20 \mu \mathrm{g})$, caspase-3 $(10 \mu \mathrm{g})$, cleaved caspase-3 $(20 \mu \mathrm{g})$, STAT3 $(10 \mu \mathrm{g}), \beta$-actin $(5 \mu \mathrm{g})$ or GAPDH $(5 \mu \mathrm{g})$. (C) BC-3, BCBL-1 and JSC-1 cells were treated with vehicle control or triptolide $(100 \mathrm{nM})$ for 24 and 48 h. The levels of LANA1 transcript were determined by qRT-PCR. The level of LANA1 transcript in cells treated with vehicle control is set as 1.

while not in P3HR-1 cells (data not shown). For cell cycle analysis, treatment of BC-3 and JSC-1 cells with triptolide resulted in G0/G1 arrest as observed by a marked increase in the number of cells in the G1 phase (Fig. 2B). In contrast, treatment of BCBL-1 cells with triptolide resulted in cell cycle arrest in $\mathrm{G} 2 / \mathrm{M}$ phase as observed by an increase in the percentage of cells in the G2/M phase (Fig. 2B). These results suggest that triptolide induces cell cycle arrest and apoptosis in the KSHV-associated PEL cells.

Triptolide decreases LANAI expression without reducing LANA1 transcript level in KSHV-associated PEL cells. To determine whether triptolide alters expression of LANA1, three different latently infected KSHV-associated PEL cells were treated with vehicle control or triptolide for $48 \mathrm{~h}$. Whole-cell extracts were prepared and subjected to western blot analysis. In addition to inhibition of LANA1 expression, two other KSHV-encoded latent proteins, v-Cyclin and v-Flip, were reduced after triptolide treatment in the three KSHVassociated PEL cells (Fig. 3A). When compared to the vehicle control, triptolide reduced the LANA1 expression level to 9.8,
16.8 and $23.4 \%$ in BC-3, BCBL-1 and JSC-1 cells, respectively. When compared to the vehicle control, triptolide reduced the v-Cyclin expression level to 3.4, 17.4 and 19.6\%, the v-Flip expression level to $14.2,22.3$ and $24.6 \%$ in BC-3, BCBL-1 and JSC-1 cells, respectively. Furthermore, consistent with the results of cell apoptosis assays, triptolide resulted in increased caspase-3 cleavage in the three KSHV-associated PEL cells. In addition, expression of STAT3, which is one of transcription factors, remained unchanged with triptolide treatment, suggesting that the effect of triptolide on LANA1 was a selective event. To further determine if triptolide specifically decreases LANA1 expression, KSHV-negative HeLa cells were transiently transfected with pSG5-LANA1, followed by treatments with or without triptolide beginning at $4 \mathrm{~h}$ after transfection. As shown in Fig. 3B, triptolide treatment significantly decreased the expression of transfected pSG5-LANA1 in HeLa cells.

Since triptolide reduced expression of LANA1, a realtime quantitative reverse transcript polymerase chain reaction (qRT-PCR) analysis was used to determine if triptolide suppressed LANA1 at the mRNA level. BC-3, BCBL-1 
A

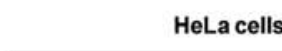

$\begin{array}{cccccl}\text { Time (48h) } & 0 & 100 & 0 & 100 & \text { Triptolide (nM) } \\ \text { Time (16 h) } & 0 & 0 & 10 & 10 & \text { MG-132 ( } \mu \text { M) }\end{array}$

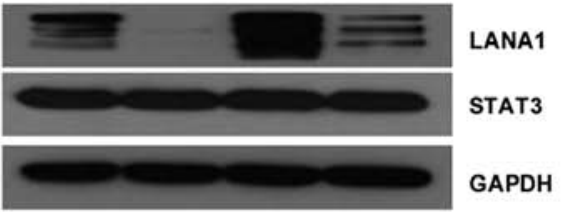

B
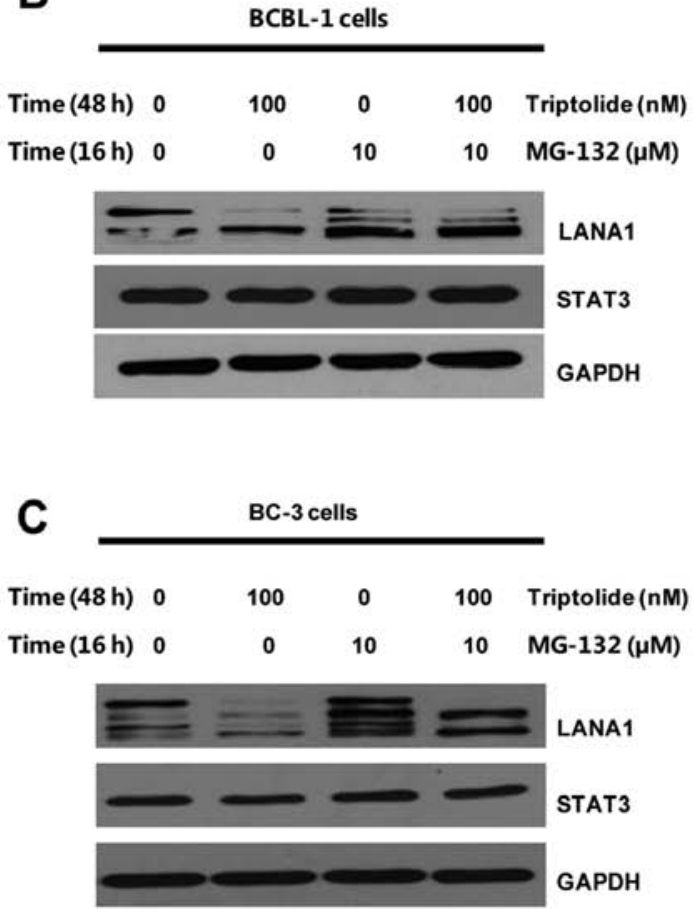

D

\begin{tabular}{|c|c|c|c|c|c|c|c|c|c|c|}
\hline 0 & 0 & 0 & 0 & 0 & 100 & 100 & 100 & 100 & 100 & Triptolide (nM) \\
\hline 25 & 25 & 25 & 25 & 25 & 25 & 25 & 25 & 25 & 25 & $\mathrm{CHX}(\mu \mathrm{g} / \mathrm{ml})$ \\
\hline 0 & 3 & 6 & 12 & 24 & 0 & 3 & 6 & 12 & 24 & Time (h) \\
\hline & & & & & & & & & & LANA1 \\
\hline- & & & & & & & & & & STAT3 \\
\hline & & & & & & & & & & GAPDH \\
\hline
\end{tabular}

E

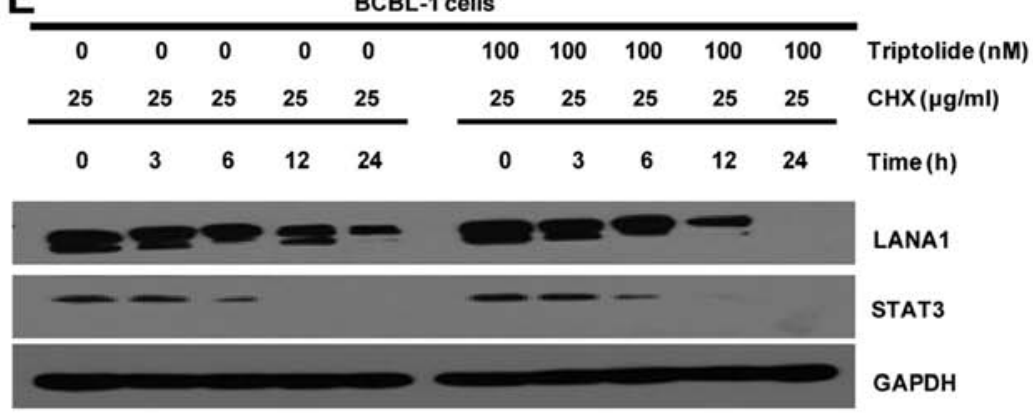

$\mathbf{F}$

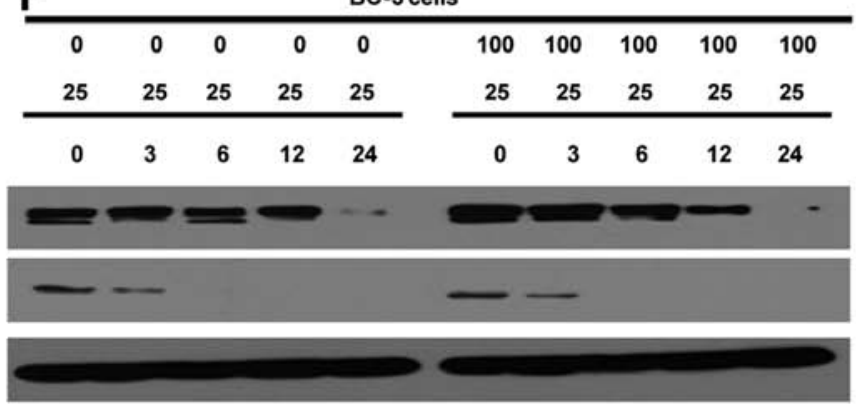

Triptolide (nM) $\mathrm{CHX}(\mu \mathrm{g} / \mathrm{ml})$ Time (h)

LANA1

STAT3

GAPDH

Figure 4. Triptolide induces proteasomal degradation of LANA1, and reduces half-life of LANA1. (A-C) Proteasomal degradation of LANA1. (A) HeLa cells were transiently transfected with pSG5-LANA1, followed by a 44-h treatment with vehicle control or triptolide (100 $\mathrm{nM})$ beginning at $4 \mathrm{~h}$ after transfection in the absence or presence of proteasome inhibitor MG-132 (10 $\mu \mathrm{M})$ for the last $16 \mathrm{~h}$. (B) BCBL-1 and (C) BC-3 cells were treated for $48 \mathrm{~h}$ with vehicle control or triptolide $(100 \mathrm{nM})$ in the absence or presence of proteasome inhibitor MG-132 $(10 \mu \mathrm{M})$ for the last $16 \mathrm{~h}$. (D-F) Half-life analysis of LANA1 in HeLa, BC-3 and BCBL-1 cells. (D) HeLa cells were transiently transfected with pSG5-LANA1 overnight, followed by incubation with vehicle control or triptolide $(100 \mathrm{nM})$ in the presence of CHX $(25 \mu \mathrm{g} / \mathrm{ml})$ for $0,3,6,12$ and $24 \mathrm{~h}$, respectively. (E) BCBL-1 and (F) BC-3 cells were treated with vehicle control or triptolide $(100 \mathrm{nM})$ in the presence of CHX $(25 \mu \mathrm{g} / \mathrm{ml})$ for $0,3,6,12$ and $24 \mathrm{~h}$, respectively. Whole-cell lysates were immunoblotted with anti-LANA1, anti-STAT3 or anti-GAPDH antibody.

and JSC-1 cells were treated with vehicle control or triptolide (100 $\mathrm{nM}$ ) for 24 and $48 \mathrm{~h}$, respectively. The total RNAs were harvested and subjected to qRT-PCR. The relative expression was detected by comparison to the housekeeping gene GAPDH. It was indicated that the mRNA levels of LANA1 in BCBL-1, BC-3 and JSC-1 cells were undetectable upon triptolide treatment (Fig. 3C).

Triptolide induces proteasomal degradation of LANA1. To examine whether triptolide decreased expression of LANA1 via the proteasome pathway, HeLa cells were transiently transfected with the pSG5-LANA1 and treated with vehicle control or triptolide in the absence or presence of proteosomal inhibitor MG-132. As shown in Fig. 4A, MG-132 obviously attenuated the effect of triptolide on LANA1 expression.
Similarly, MG-132 also resulted in endogenous LANA1 protein level accumulation in BCBL-1 (Fig. 4B) and BC-3 (Fig. 4C) cells after treatment with triptolide.

Triptolide reduces stability or half-life of LANA1. Previous studies had indicated that triptolide decreased the expression of LANA1 and induced proteasomal degradation of LANA1. To determine whether triptolide affect LANA1 stability through some other mechanisms, HeLa cells were transiently transfected with the pSG5-LANA1 and treated with vehicle control or triptolide in the presence of cycloheximide (CHX). As shown in Fig. 4D, triptolide reduced the half-life of LANA1 when compared to vehicle control, while not affecting GAPDH levels. Similarly, triptolide also reduced the half-life of endogenous LANA1 protein in the CHX-treated BCBL-1 
A
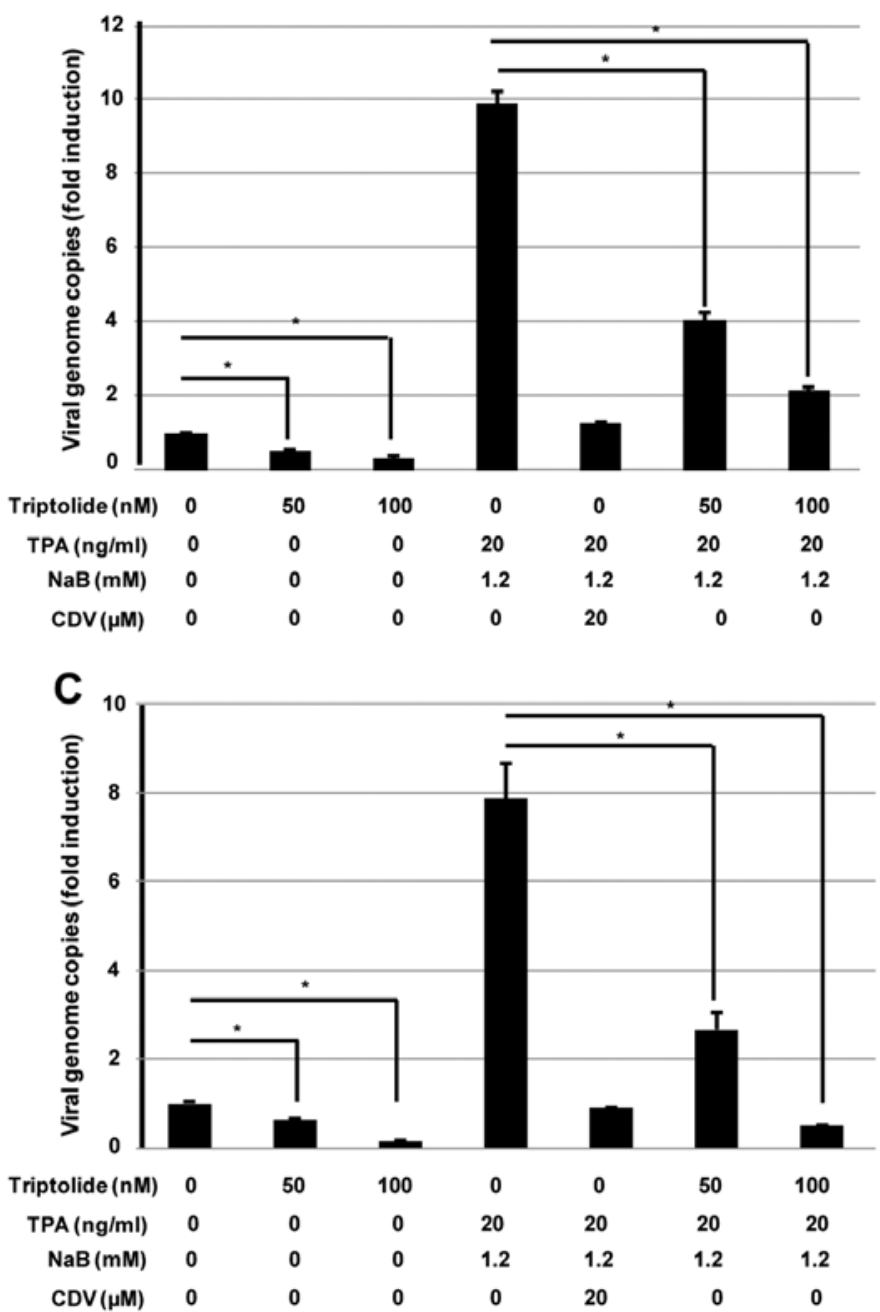

B

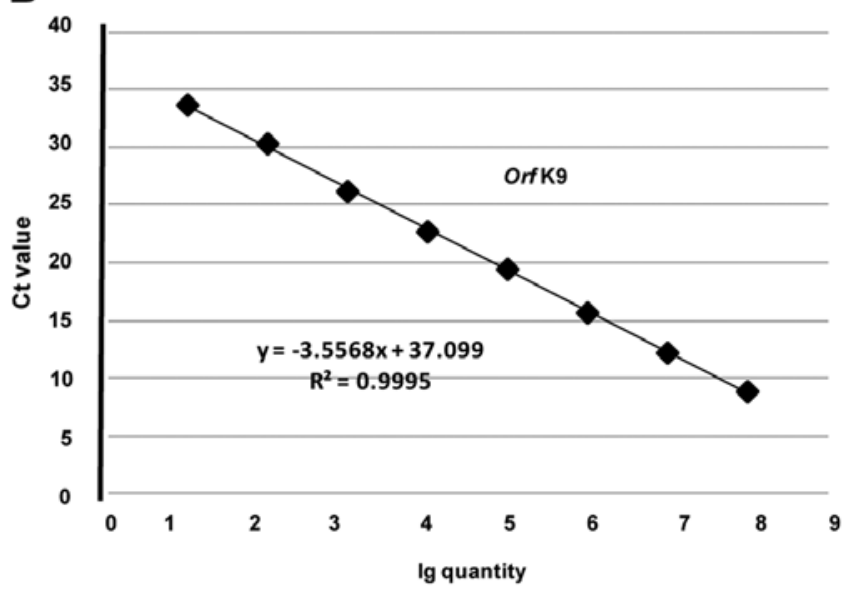

D

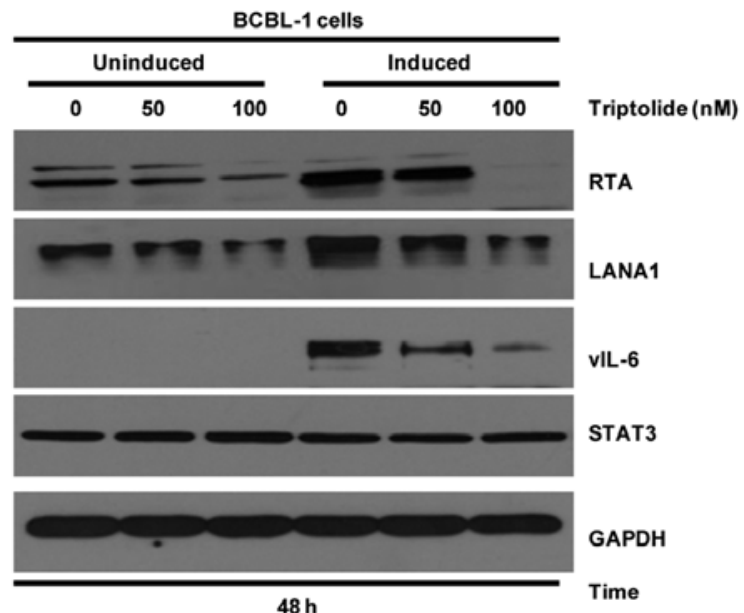

Figure 5. Triptolide reduces lytic and latent replication of KSHV in BCBL-1 cells. Uninduced and induced BCBL-1 cells were treated with vehicle control or indicated concentrations of triptolide for $48 \mathrm{~h}$. The whole cell supernatants, genomic DNA and lysates were prepared. (A) The copy numbers of the intracellular viral DNA were quantified by qRT-PCR, each sample was normalized to the amount of the GAPDH gene. "P<0.05, compared to control. (B) The standard curve for virions quantification used to calculate the number of KSHV virions in the supernatants of BCBL1 cells. (C) The virion production extracted from equivalent supernatants was determined by qRT-PCR, and the viral copy numbers were calculated via the standard curve derived from the $O r f K 9$ construct. ${ }^{*} \mathrm{P}<0.05$, compared to control. (D) Cells lysates above were immunoblotted with anti-LANA1, anti-RTA (20 $\left.\mu \mathrm{g}\right)$, anti-vIL-6 (20 $\left.\mu \mathrm{g}\right)$, anti-STAT3 or antiGAPDH antibody.

(Fig. 4E) and BC-3 (Fig. 4F) cells. Notably, triptolide did not significantly affect STAT3 stability (Fig. 4D-F).

Triptolide reduces lytic and latent replication of $K S H V$ in $B C B L-1$ cells. To examine the effect of triptolide on antiviral activity, BCBL-1 cells uninduced or induced by TPA and $\mathrm{NaB}$ for $3 \mathrm{~h}$ were treated with indicated concentrations of triptolide for $48 \mathrm{~h}$. Whole cell lysates, supernatants, and genomic DNA were prepared at $48 \mathrm{~h}$ post-incubation. qRT-PCR and western blotting were used to analyze the effect of triptolide on lytic and latent replication of KSHV. As shown in Fig. 5A, triptolide decreased viral genome copies in both uninduced and induced BCBL-1 cells. When compared to the vehicle control in induced BCBL-1 cells, intracellular viral DNA replication was reduced by 5 -fold after triptolide $(100 \mathrm{nM})$ treatment for $48 \mathrm{~h}$. Production of progeny virion extracted from the BCBL-1 cell supernatants was calculated according to the standard curve derived from the $\mathrm{Orf} K 9$ construct (Fig. 5B). Results indicated that the production of progeny virion was dose-dependently reduced after triptolide treatment (Fig. 5C). As expected, CDV, which was used as a positive control, efficiently reduced the lytic replication and virion production of KSHV as previously described (33). Replication and transcription activator (RTA), a lytic switch protein, is necessary for KSHV reactivation and lytic DNA replication. Western blotting was used to detect the effect of triptolide on the expression of RTA in BCBL-1 cells. As shown in Fig. 5D, triptolide reduced expression of LANA1 and RTA in both uninduced and induced BCBL-1 cells. In addition, vIL-6, encoded by KSHV $\operatorname{Orf} K 2$, contributed to the growth, survival and spread of PEL. Our results as shown in Fig. 5D also indicated that triptolide decreased vIL-6 expression in induced BCBL-1 cells.

Triptolide suppresses STAT3 activity in PEL cells. LANA1, a transcriptional co-activator of STAT3, modulates STAT3 activity in PEL cells (20). STAT3 is constitutively phosphory- 
A

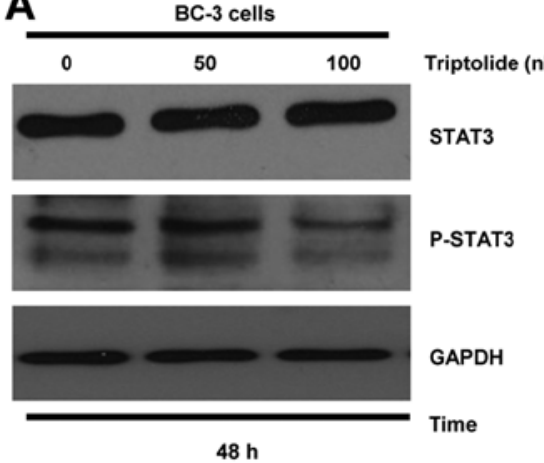

B

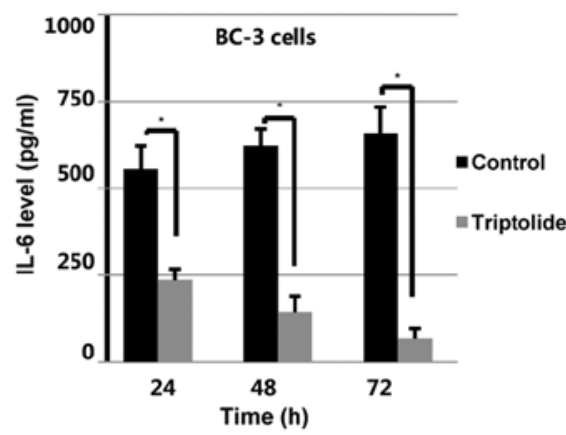

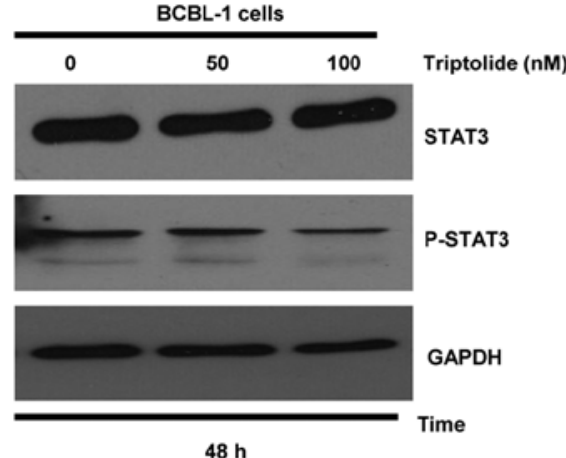

$48 \mathrm{~h}$

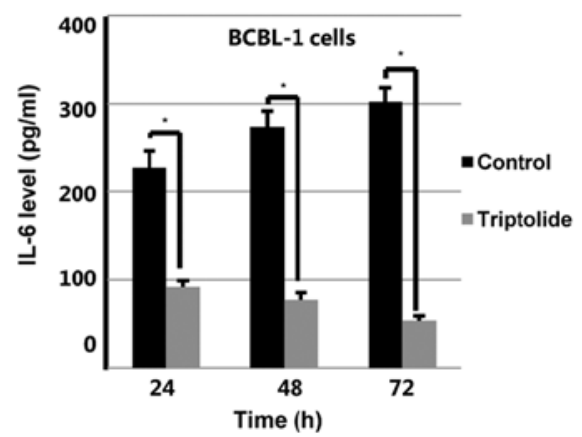

JSC-1 cells
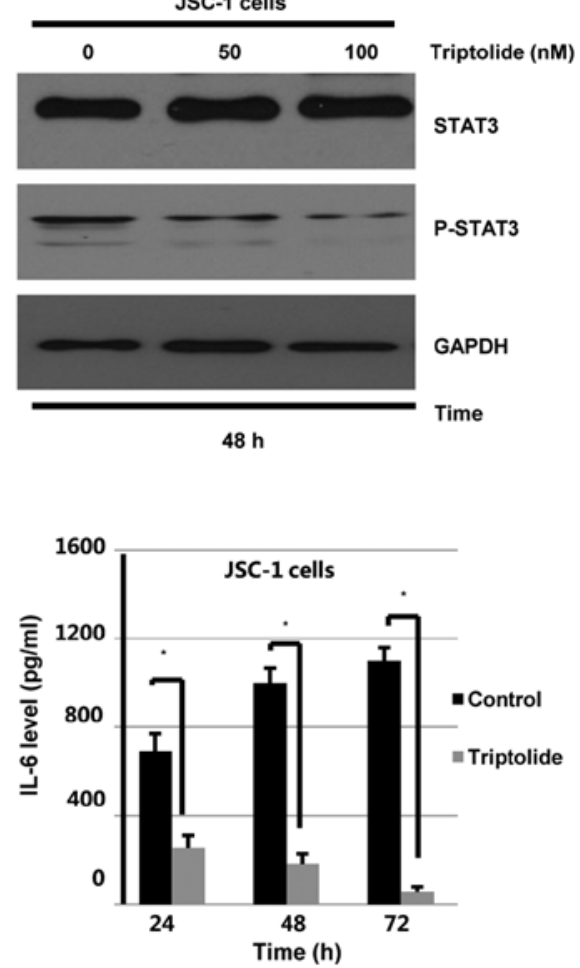

Figure 6. Triptolide suppresses STAT3 activity and secretion of IL-6 in PEL cells. (A) The three kinds of PEL cells were treated with vehicle control or indicated triptolide for $48 \mathrm{~h}$, respectively. Whole-cell extracts were prepared and western blotting was performed to analyze expression of STAT3, p-STAT3 $(20 \mu \mathrm{g})$, or GAPDH. (B) PEL cells were treated with vehicle control or triptolide (100 nM) for 24, 48 and $72 \mathrm{~h}$, followed by detecting IL-6 levels using ELISA in the supernatants. Values shown are mean \pm SD of 3 independent experiments carried out in triplicate. ${ }^{*} \mathrm{P}<0.05$, compared to control.

lated and is essential to cell survival in PEL cells (34). Since STAT3 represents a potential target for treatment of PEL, the STAT3 activity affected by triptolide was determined. Results shown in Fig. 6A indicated that triptolide dephosphorylated STAT3 in BCBL-1, BC-3 and JSC-1 cells. It has been reported that KSHV encoded LANA1 upregulated IL-6 expression by inducing transcription of the IL-6 promoter (35). IL-6 and vIL-6 secreted by KSHV-positive cells are multifunctional cytokines that contribute to the pathogenesis of PEL (35). To determine effect of triptolide on secretion of IL-6, KSHVassociated PEL cells were treated with vehicle control or $100 \mathrm{nM}$ triptolide for 24, 48 and $72 \mathrm{~h}$. Cell supernatants were collected and subjected to ELISA. As shown in Fig. 6B, triptolide resulted in reduced secretion of IL- 6 in the supernanants of BCBL-1, BC-3 and JSC-1 cells. These results suggests that downregulation of LANA1 by triptolide results in inhibition of IL-6/STAT3 pathway in PEL cells.

In vivo effects of triptolide on NOD/SCID mice inoculated with $B C B L-1$ cells. Since our previous results indicated efficacy of triptolide for treatment of PEL in vitro, effects of triptolide in vivo were also assessed in an immunodeficient xenograft mouse model. NOD/SCID mice were inoculated intraperitoneally with $1 \times 10^{7} \mathrm{BCBL}-1$ cells. A dose of $0.4 \mathrm{mg} / \mathrm{kg}$ triptolide or PBS alone was administrated via intraperitoneal injection daily for 3 weeks from day 3 after cell inoculation. As the dose of triptolide from intraperitoneal injection had already been reported (23), the dosage of triptolide in vivo in the present study was expected to be safe. The body weight of the PBS alone treated mice significantly increased compared to that of triptolide treated mice $(28.9 \pm 1.79$ vs. $19.2 \pm 2.21 \mathrm{~g}, \mathrm{n}=6, \mathrm{P}<0.01$; Fig. 7A). Moreover, mice treated with triptolide had a significantly lower volume of ascites $(1.45 \pm 0.27$ vs. $0.17 \pm 0.07 \mathrm{ml}$, $\mathrm{n}=6, \mathrm{P}<0.01$; Fig. 7B). In addition, IL-6 level in the supernatants of ascites was significantly decreased in comparison to that of triptolide treatment (Fig. 7C). Western blotting results of ascites cells indicated that triptolide significantly cut down the expression of LANA1 and induced ascites cell apoptosis via caspase-3 pathways (Fig. 7D). Representative photos of mice treated with PBS alone and triptolide treated are shown in Fig. 7E.

Organ invasion by BCBL-1 cells on day 24 was evaluated by hematoxylin and eosin staining, as well as LANA1 immunostaining. As shown in Fig. 7F, spleens of mice treated with triptolide were significantly smaller compared to the group treated with PBS alone. The mice inoculated with BCBL-1 cells exhibited infiltration in the spleen and the number of LANA1 positive cells in triptolide treated mice was significantly reduced (Fig. 7G). These results suggest that triptolide efficiently inhibits growth and infiltration of PEL cells in vivo.

\section{Discussion}

LANA1 is a pivotal latent protein, which is consistently expressed in all proliferating KSHV-positive cells and is essential for cell survival. Moreover, LANA1 plays an important role in regulating segregation, replication and persistence of viral episome (36), providing an attractive target for the 
A

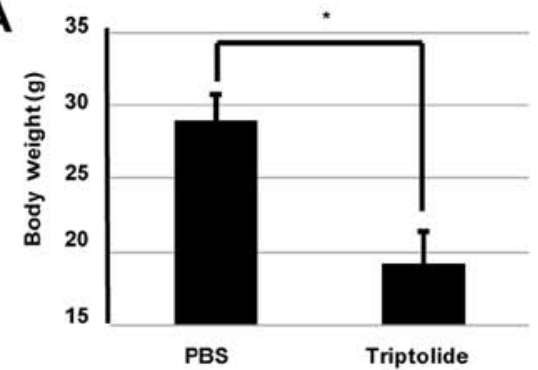

D

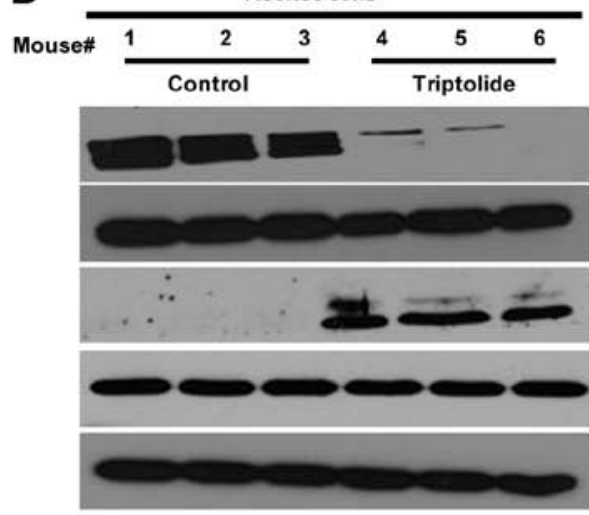

LANA1

Caspase 3

Cleaved caspase 3

STAT3

GAPDH

\section{$\mathbf{F}$}

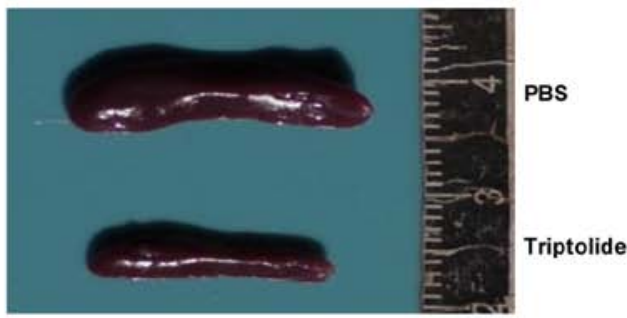

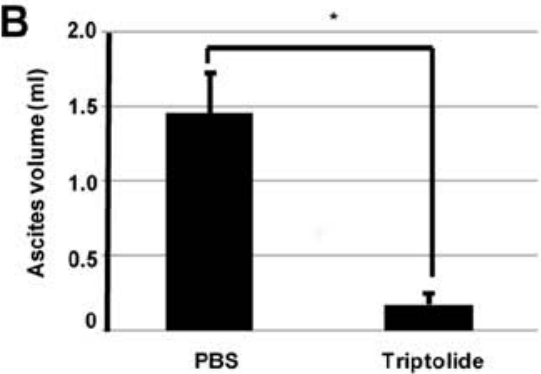

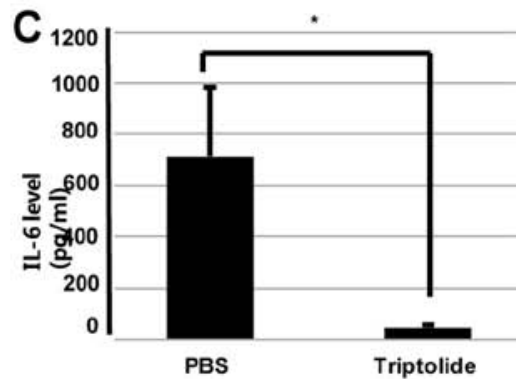

E
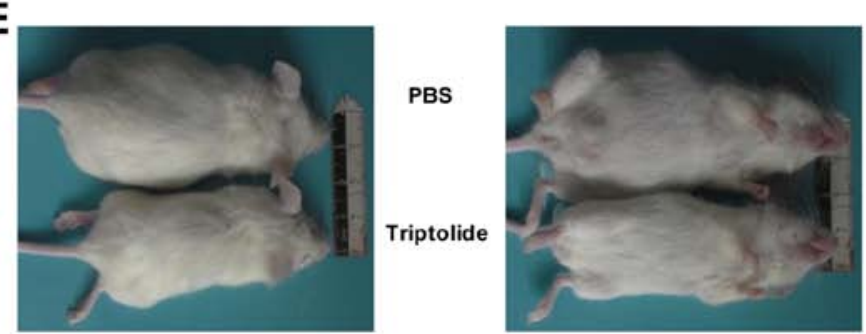

G

PBS

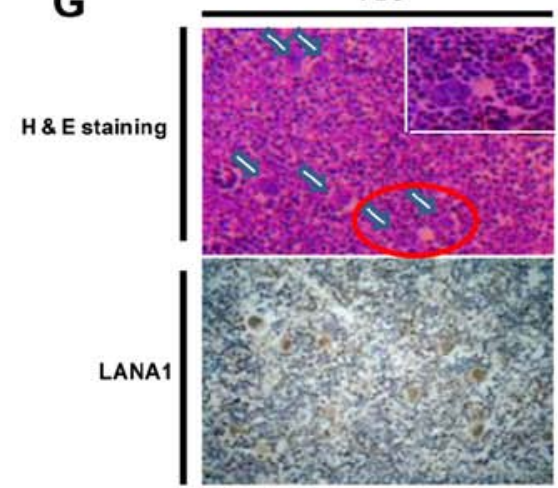

Triptolide

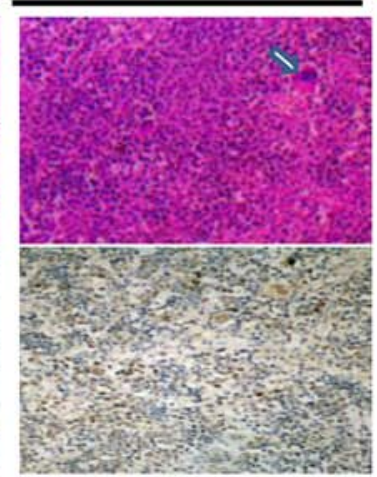

Figure 7. Treatment of NOD/SCID mice with triptolide impairs growth of PEL in vivo. NOD/SCID mice with established intraperitoneal BCBL-1 tumors were treated with PBS or $0.4 \mathrm{mg} / \mathrm{kg}$ triptolide for 21 days. (A) Body weights, (B) ascites volume, and (C) IL-6 levels of ascites were evaluated in NOD/SCID mice treated with triptolide $(0.4 \mathrm{mg} / \mathrm{kg} /$ day) or PBS for 21 days. The whole values are shown as mean \pm SD of 6 mice. * $\mathrm{P}<0.05$, compared to control. (D) Lysates of ascites cells were subjected to western blot analysis using the indicated antibodies. (E and F) Representative images of mice and spleen from groups of mice treated with either PBS or triptolide are shown. (G) H\&E staining was performed to detect infiltrated cells indicated with white arrows, and an enlarged image of infiltrated cells is shown in the upper right. Immunohistochemical staining using anti-LANA1 were performed to detect BCBL-1 cells in the spleen.

treatment of KSHV-induced diseases. In the present study, the direct effects of triptolide on KSHV-associated PEL cells in vitro and in vivo were evaluated. Firstly, it was demonstrated that triptolide effectively inhibited KSHV-associated PEL cells proliferation with a nanomolar concentration. Moreover, triptolide induced cell cycle arrest and apoptosis in the KSHVassociated PEL cells.

Our previous study demonstrated that triptolide reduced the expression of LMP1 in latency III type infected EBV-positive B lymphocytes (29). Since LANA1 is reported to be a client protein of Hsp90, 17-DMAG is efficacious against KS by promoting the degradation of LANA1 (30). Of note, our findings indicate that triptolide decreases LANA1 expression in a variety of cell types, including three different KSHV-associated PEL cells and KSHV-negative HeLa cells transiently transfected with pSG5-LANA1. Further study indicated that triptolide did not reduce LANA1 expression at the mRNA levels. In addition, LANA1 accumulated after treatment with MG-132 in the presence of triptolide. Triptolide also decreased the stability or half-life of LANA1. In addition to LANA1, v-Cyclin and v-Flip are two KSHV-encoded latent proteins. $\mathrm{KSHV}$-encoded $\mathrm{v}$-Cyclin contributed to tumorigenesis through inhibiting cell cycle inhibitor p27Kip1 in PEL (37). KSHV-encoded v-Flip contributed to activation of NF-kappaB pathway, which is essential for survival in a majority of PEL cells (38). Our results also indicated that triptolide inhibited expression of $\mathrm{v}$-Cyclin and v-Flip in KSHV-associated PEL cells. These results suggest that triptolide reduces the expression of three major latent proteins, together with inducing proteasomal degradation of LANA1 and impairing its stability.

Lytic replication and gene expression of KSHV are essential to promote tumorigenesis (39). Previous studies have demonstrated that higher KSHV viral load has been associated with increased risk of KSHV-induced malignancies (40). Consistent with the ability of triptolide to decrease LANA1 expression in KSHV latency infected cells, our results demonstrated that triptolide impaired lytic replication of $\mathrm{KSHV}$, as well as virion 
production released from induced BCBL-1 cells, suggesting that triptolide treatment is efficacious against KSHV replication. Triptolide also reduced the expression of lytic genes RTA, and inhibited their expression induced by TPA and NaB, thereby allaying these safety concerns. Essentially similar effects of BIIB021 and 17-AAG on the expression of RTA have been reported recently $(38,41)$. In addition, triptolide reduced expression of vIL-6, which contributed to pathogenesis of PEL, in TPA and NaB induced BCBL-1 cells. At present, the exact mechanism for the inhibition of lytic replication and gene expression of KSHV by triptolide is not clear and need further study. Taken together, triptolide can efficiently induce apoptosis and cell cycle arrest, together with down-regulation of LANA1 expression and viral replication in the KSHVassociated PEL cells.

STAT3 activity plays an essential role in the survival of PEL cells. STAT3 is constitutively active and inhibition of STAT3 results in apoptosis in PEL cells (33). Previous reports have indicated that LANA1, a transcriptional co-activator of STAT3, modulates STAT3 activity in PEL cells (20). Overexpression of LANA1 enhanced STAT3 activity, and inhibition of LANA1 expression decreased the STAT3dependent transcription (20). Consistent with the effects of AG490, a tyrosine kinase inhibitor, on STAT3 activity in PEL cells (42), triptolide reduced STAT3 activity in PEL cells. In addition, IL-6 is a pivotal cytokine contributing to cell survival. LANA1 enhanced IL-6 expression by inducing transcription of the IL-6 promoter (34). Our results demonstrated that triptolide reduced secretion of IL-6 in BCBL-1, BC-3 and JSC-1. Therefore, inhibition of STAT3 activity and IL-6 secretion may result from the downregulation of LANA1 by triptolide.

In addition to the effect of triptolide on the KSHV-positive malignant cells in vitro, the present study also evaluated the therapeutic effect of triptolide against PEL in vivo using a mouse xenograft model. PEL xenograft mice are characterized by lymphomatous effusions in body cavities and rarely present with a definable tumor mass, which are similar to the clinical feature of human PEL patients (43). Consistent with the therapeutic effect of other drugs against PEL xenograft mouse models (44), triptolide treatment significantly repressed the formation of malignant ascites and lymphomatous effusions caused by BCBL-1 cells in NOD/SCID mice. Moreover, triptolide treatment decreased the expression of LANA1 in ascites cells and induced apoptosis of ascites cells in a caspasedependent manner.

Although KSHV was discovered 20 years ago, there is little progress in the management of KSHV-related diseases. Due to the toxic effect or incomplete efficiency of classical antiviral agents, such as acyclovir, ganciclovir and adefovir, antiviral treatments for KSHV-infected diseases are limited. To date, standard therapeutic guidelines are not drawn for the treatment of $\mathrm{KSHV}$-associated malignancies. Currently antiviral drugs mainly target lytic replication of virus, which is essential to disease progression and virus dissemination. Nevertheless, the majority of KSHV-infected tumor cells are in latency, and antiviral drugs targeting KSHV lytic replication have not shown consistent results for the treatment of KSHV-associated $\mathrm{KS}$ in clinic (6). Therefore, targeting viral latency may be a novel strategy for the treatments of KSHV-infected diseases.
In this study, our results have demonstrated the ability of triptolide in vitro and in vivo to inhibit cell proliferation and induce cell apoptosis in the KSHV-associated PEL cells. In addition, triptolide can efficiently reduce the expression of LANA1, inhibit viral replication, and impair production of progeny virion in the KSHV-associated PEL cells. Our results show that triptolide may be a promising compound for the treatment of KSHV-associated diseases.

\section{Acknowledgements}

The present study was supported by the Initiative Research Program of Wuhan University (no. 410100020), the Advanced Talent Independent Research Program of Wuhan University (no. 410500011), and the National Natural Science Foundation of China (no. 210700228).

\section{References}

1. Chang Y, Cesarman E, Pessin MS, Lee F, Culpepper J, Knowles DM and Moore PS: Identification of herpesvirus-like DNA sequences in AIDS-associated Kaposi's sarcoma. Science 266: 1865-1869, 1994.

2. Boulanger E, Gérard L, Gabarre J, Molina JM, Rapp C, Abino JF, Cadranel J, Chevret S and Oksenhendler E: Prognostic factors and outcome of human herpesvirus 8-associated primary effusion lymphoma in patients with AIDS. J Clin Oncol 23: 4372-4380, 2005.

3. Boshoff $\mathrm{C}$ and Chang $\mathrm{Y}$ : Kaposi's sarcoma-associated herpesvirus: A new DNA tumor virus. Annu Rev Med 52: 453-470, 2001.

4. Bottero V, Sadagopan S, Johnson KE, Dutta S, Veettil MV and Chandran B: Kaposi's sarcoma-associated herpesvirus-positive primary effusion lymphoma tumor formation in NOD/SCID mice is inhibited by neomycin and neamine blocking angiogenin's nuclear translocation. J Virol 87: 11806-11820, 2013.

5. Sarosiek KA, Cavallin LE, Bhatt S, Toomey NL, Natkunam Y, Blasini W, Gentles AJ, Ramos JC, Mesri EA and Lossos IS: Efficacy of bortezomib in a direct xenograft model of primary effusion lymphoma. Proc Natl Acad Sci USA 107: 13069-13074, 2010.

6. Coen N, Duraffour S, Snoeck R and Andrei G: KSHV targeted therapy: An update on inhibitors of viral lytic replication. Viruses 6: 4731-4759, 2014.

7. Dyson OF, Walker LR, Whitehouse A, Cook PP and Akula SM: Resveratrol inhibits KSHV reactivation by lowering the levels of cellular EGR-1. PLoS One 7: e33364, 2012.

8. Lee GM, Shahian T, Baharuddin A, Gable JE and Craik CS: Enzyme inhibition by allosteric capture of an inactive conformation. J Mol Biol 411: 999-1016, 2011.

9. Verma SC, Lan K and Robertson E: Structure and function of latency-associated nuclear antigen. Curr Top Microbiol Immunol 312: 101-136, 2007.

10. Sun Q, Tsurimoto T, Juillard F, Li L, Li S, De León Vázquez E, Chen $\mathrm{S}$ and Kaye K: Kaposi's sarcoma-associated herpesvirus LANA recruits the DNA polymerase clamp loader to mediate efficient replication and virus persistence. Proc Natl Acad Sci USA 111: 11816-11821, 2014.

11. Uppal T, Banerjee S, Sun Z, Verma SC and Robertson ES: KSHV LANA - the master regulator of KSHV latency. Viruses 6: 4961-4998, 2014.

12. Fujimuro M, Wu FY, ApRhys C, Kajumbula H, Young DB, Hayward GS and Hayward SD: A novel viral mechanism for dysregulation of beta-catenin in Kaposi's sarcoma-associated herpesvirus latency. Nat Med 9: 300-306, 2003.

13. Lu J, Jha HC, Verma SC, Sun Z, Banerjee S, Dzeng R and Robertson ES: Kaposi's sarcoma-associated herpesvirus-encoded LANA contributes to viral latent replication by activating phosphorylation of survivin. J Virol 88: 4204-4217, 2014.

14. Paudel N, Sadagopan S, Chakraborty S, Sarek G, Ojala PM and Chandran B: Kaposi's sarcoma-associated herpesvirus latency-associated nuclear antigen interacts with multifunctional angiogenin to utilize its antiapoptotic functions. J Virol 86: 5974-5991, 2012. 
15. Verma SC, Borah S and Robertson ES: Latency-associated nuclear antigen of Kaposi's sarcoma-associated herpesvirus up-regulates transcription of human telomerase reverse transcriptase promoter through interaction with transcription factor Sp1. J Virol 78: 10348-10359, 2004.

16. Sun R, Liang D, Gao Y and Lan K: Kaposi's sarcoma-associated herpesvirus-encoded LANA interacts with host KAP1 to facilitate establishment of viral latency. J Virol 88: 7331-7344, 2014

17. Sun Z, Xiao B, Jha HC, Lu J, Banerjee S and Robertson ES: Kaposi's sarcoma-associated herpesvirus-encoded LANA can induce chromosomal instability through targeted degradation of the mitotic checkpoint kinase Bub1. J Virol 88: 7367-7378, 2014.

18. Friborg J Jr, Kong W, Hottiger MO and Nabel GJ: p53 inhibition by the LANA protein of KSHV protects against cell death. Nature 402: 889-894, 1999.

19. Radkov SA, Kellam P and Boshoff C: The latent nuclear antigen of Kaposi sarcoma-associated herpesvirus targets the retinoblastoma-E2F pathway and with the oncogene Hras transforms primary rat cells. Nat Med 6: 1121-1127, 2000.

20. Muromoto R, Okabe K, Fujimuro M, Sugiyama K, Yokosawa H, Seya $\mathrm{T}$ and Matsuda T: Physical and functional interactions between STAT3 and Kaposi's sarcoma-associated herpesvirusencoded LANA. FEBS Lett 580: 93-98, 2006.

21. Kupchan SM, Court WA, Dailey RG Jr, Gilmore CJ and Bryan RF: Triptolide and tripdiolide, novel antileukemic diterpenoid triepoxides from Tripterygium wilfordii. J Am Chem Soc 94: 7194-7195, 1972.

22. Liu Q: Triptolide and its expanding multiple pharmacological functions. Int Immunopharmacol 11: 377-383, 2011.

23. Zhou ZL, Yang YX, Ding J, Li YC and Miao ZH: Triptolide: Structural modifications, structure-activity relationships, bioactivities, clinical development and mechanisms. Nat Prod Rep 29: 457-475, 2012.

24. Banerjee S, Sangwan V, McGinn O, Chugh R, Dudeja V, Vickers SM and Saluja AK: Triptolide-induced cell death in pancreatic cancer is mediated by O-GlcNAc modification of transcription factor Sp1. J Biol Chem 288: 33927-33938, 2013.

25. Phillips PA, Dudeja V, McCarroll JA, Borja-Cacho D, Dawra RK, Grizzle WE, Vickers SM and Saluja AK: Triptolide induces pancreatic cancer cell death via inhibition of heat shock protein 70. Cancer Res 67: 9407-9416, 2007.

26. Chugh R, Sangwan V, Patil SP, Dudeja V, Dawra RK, Banerjee S, Schumacher RJ, Blazar BR, Georg GI, Vickers SM, et al: A preclinical evaluation of Minnelide as a therapeutic agent against pancreatic cancer. Sci Transl Med 4: 156ra139, 2012.

27. Sun X, Barlow EA, Ma S, Hagemeier SR, Duellman SJ, Burgess RR, Tellam J, Khanna R and Kenney SC: Hsp90 inhibitors block outgrowth of EBV-infected malignant cells in vitro and in vivo through an EBNA1-dependent mechanism. Proc Nat Acad Sci USA 107: 3146-3151, 2010.

28. Sun X, Bristol JA, Iwahori S, Hagemeier SR, Meng Q, Barlow EA, Fingeroth JD, Tarakanova VL, Kalejta RF and Kenney SC: Hsp90 inhibitor 17-DMAG decreases expression of conserved herpesvirus protein kinases and reduces virus production in Epstein-Barr virus-infected cells. J Virol 87: 10126-10138, 2013.

29. Zhou H, Guo W, Long C, Wang H, Wang J and Sun X: Triptolide inhibits proliferation of Epstein-Barr virus-positive B lymphocytes by down-regulating expression of a viral protein LMP1. Biochem Biophys Res Commun 456: 815-820, 2015.
30. Chen W, Sin SH, Wen KW, Damania B and Dittmer DP: Hsp90 inhibitors are efficacious against Kaposi Sarcoma by enhancing the degradation of the essential viral gene LANA, of the viral co-receptor EphA2 as well as other client proteins. PLoS Pathog 8: e1003048, 2012.

31. Lin X, Liang D, He Z, Deng Q, Robertson ES and Lan K: miRK12-7-5p encoded by Kaposi's sarcoma-associated herpesvirus stabilizes the latent state by targeting viral ORF50/RTA. PLoS One 6: e16224, 2011.

32. Choi ES, Nam JS, Jung JY, Cho NP and Cho SD: Modulation of specificity protein 1 by mithramycin A as a novel therapeutic strategy for cervical cancer. Sci Rep 4: 7162, 2014.

33. Pica F, Serafino A, Garaci E and Volpi A: Cidofovir on HHV-8 in BCBL-1 cells. Antivir Ther 9: 823-825, 2004.

34. Aoki Y, Feldman GM and Tosato G: Inhibition of STAT3 signaling induces apoptosis and decreases survivin expression in primary effusion lymphoma. Blood 101: 1535-1542, 2003.

35. An J, Lichtenstein AK, Brent G and Rettig MB: The Kaposi sarcoma-associated herpesvirus (KSHV) induces cellular interleukin 6 expression: Role of the KSHV latency-associated nuclear antigen and the AP1 response element. Blood 99: 649-654, 2002.

36. Vázquez EL, Carey VJ and Kaye KM: Identification of Kaposi's sarcoma-associated herpesvirus LANA regions important for episome segregation, replication, and persistence. J Virol 87 : 12270-12283, 2013.

37. Järviluoma A, Koopal S, Räsänen S, Mäkelä TP and Ojala PM: KSHV viral cyclin binds to p27KIP1 in primary effusion lymphomas. Blood 104: 3349-3354, 2004.

38. Gopalakrishnan R, Matta $\mathrm{H}$ and Chaudhary PM: A purine scaffold HSP90 inhibitor BIIB021 has selective activity against KSHV-associated primary effusion lymphoma and blocks vFLIP K13-induced NF-кB. Clin Cancer Res 19: 5016-5026, 2013.

39. Nicholas J: Human herpesvirus 8-encoded proteins with potential roles in virus-associated neoplasia. Front Biosci 12: 265-281, 2007.

40. Quinlivan EB, Zhang C, Stewart PW, Komoltri C, Davis MG and Wehbie RS: Elevated virus loads of Kaposi's sarcoma-associated human herpesvirus 8 predict Kaposi's sarcoma disease progression, but elevated levels of human immunodeficiency virus type 1 do not. J Infect Dis 185: 1736-1744, 2002.

41. Higashi C, Saji C, Yamada K, Kagawa H, Ohga R, Taira T and Fujimuro M: The effects of heat shock protein 90 inhibitors on apoptosis and viral replication in primary effusion lymphoma cells. Biol Pharm Bull 35: 725-730, 2012.

42. Granato M, Chiozzi B, Filardi MR, Lotti LV, Di Renzo L, Faggioni A and Cirone M: Tyrosine kinase inhibitor tyrphostin AG490 triggers both apoptosis and autophagy by reducing HSF1 and Mcl-1 in PEL cells. Cancer Lett 366: 191-197, 2015.

43. Nador RG, Cesarman E, Chadburn A, Dawson DB, Ansari MQ, Sald J and Knowles DM: Primary effusion lymphoma: A distinct clinicopathologic entity associated with the Kaposi's sarcomaassociated herpes virus. Blood 88: 645-656, 1996.

44. Goto H, Kariya R, Shimamoto M, Kudo E, Taura M, Katano H and Okada S: Antitumor effect of berberine against primary effusion lymphoma via inhibition of NF- $\mathrm{KB}$ pathway. Cancer Sci 103: 775-781, 2012. 